\title{
Citocompatibilidade de Blendas de Poli( $p$-dioxanona $) /$ Poli(hidroxi butirato) (PPD/PHB) para Aplicações em Engenharia de Tecido Cartilaginoso
}

\author{
Andrea R. Esposito, Eliana A. R. Duek \\ Laboratório de Biomateriais, PUC-SP \\ Departamento de Engenharia de Materiais, UNICAMP \\ Carolina Lucchesi \\ Instituto de Biologia, UNICAMP \\ Luciana Prazeres, Ana P. T. Pezzin \\ Departamento de Engenharia Ambiental, UNIVILLE
}

\begin{abstract}
Resumo: Buscando estratégias que repercutam na melhoria da interação entre materiais poliméricos biorreabsorvíveis e o crescimento celular, o presente estudo in vitro teve como objetivo estudar a influência de blendas de PPD/PHB na adesão celular e crescimento de fibrocondrócitos obtidos a partir de cultura primária. As blendas de PPD/PHB foram preparadas pelo método de evaporação de solvente nas composições 100/0, 60/40 e 50/50 e caracterizadas por microscopia eletrônica de varredura (MEV). Observações ultra-estruturais mostraram alterações na morfologia celular, sugerindo que os fibrocondrócitos podem responder a alterações no substrato alterando seu perfil fenotípico. As análises com MTT demonstraram que as blendas não apresentaram citotoxicidade e permitiram a adesão e proliferação dos fibrocondrócitos sobre os substratos em todas as suas composições. O ensaio colorimétrico com Sirius Red evidenciou a capacidade de manutenção da síntese de matriz extracelular colágena sobre as amostras, concluindo-se que as blendas de PPD/PHB podem ser indicadas para o cultivo celular.
\end{abstract}

Palavras-chave: Blenda, poli(p-dioxanona), poli(hidroxi butirato), fibrocondrócitos.

\section{Cytocompatibility of Poly(p-dioxanone)/ Poly(hydroxybutic) (PPD/PHB) Blends to Cartilage Tissue Engineering}

Abstract: In order of seek strategies to improve the interaction between bioreabsorbable polymer materials and cellular growth, this work aimed at evaluating in vitro the influence of PPD/PHB blends on cell adhesion and fibrochondrocytes growth. Fibrochondrocytes cells were obtained by primary extraction from enzymatic digestion methods. The PPD/PHB blends were prepared by casting with 100/0, 60/40 and 50/50 compositions, and were characterized by scanning electron microscopy (SEM). After 6, 48, 120 and 168 hours in culture, ultrastructural observations showed changes in cell morphology, suggesting that the fibrochondrocytes can respond to substrate modifications, changing their phenotypic profile. The MTT analyses showed that the blends did not present cytotoxicity and allowed fibrochondrocytes adhesion and proliferation on the membranes in all compositions. The colorimetric Sirius Red test revealed the capability of extracellular matrix synthesis on the blends, from which one can conclude that the PPD/PHB blends are not cytotoxic and can be indicated for cell culture.

Keywords: Blend, poly(p-dioxanone), poly(hydroxybutic), fibrochondrocytes.

\section{Introdução}

A necessidade de uma fonte celular para propiciar a formação de um neotecido representa um dos princípios da regeneração humana ${ }^{[1]}$. A compreensão acerca das características proliferativas e da diferenciação das células progenitoras naturais de um tecido permite o desenvolvimento de meios que as mantenham ou que estimulem a sua expansão in vitro, antes de implantá-las em áreas lesadas $^{[2]}$. Como pré-requisito para estimular as etapas iniciais de regeneração tecidual é inegável o papel suporte da matriz extracelular local ${ }^{[3,4]}$.

A meniscectomia já foi considerada um procedimento inócuo. Hoje se sabe que esse fato não é verdadeiro. A fibrocartilagem dos meniscos é de fundamental importância para o desempenho mecânico, estabilidade e sensibilidade da $\operatorname{articulação~}^{[5]}$. Por se tratar de uma estrutura sujeita a diversas lesões e apresentar limitada capacidade regenerativa, esse tecido vem sendo alvo de estudos nas últimas décadas e diferentes estratégias foram utilizadas focando principalmente sua recuperação ${ }^{[-9]}$.

O uso de materiais poliméricos biorreabsorvíveis tem mostrado resultados promissores como substitutos de meniscos ${ }^{[10-16]}$. Trabalhos iniciais conduzidos com cultura celular e em experimentações animais mostraram que fibrocondrócitos podem proliferar e sintetizar a matriz extracelular sobre membranas de PLLA, sem suprimento sanguíneo se o meio extracelular é mantido $^{[17]}$.

Em um procedimento de meniscectomia medial, Pezzin et al. ${ }^{[18]}$ utilizaram blendas de poli(ácido láctico)/poli(p-dioxanona) para

Autor para correspondência: Andrea R. Esposito, Laboratório de Biomateriais, Pontifícia Universidade Católica de São Paulo,

Praça Dr. José Ermirio de Moraes, 290, CEP: 18030-095, Sorocaba, SP, Brasil. E-mail: aesposito@fem.unicamp.br 
estimular a formação de um neomenisco. A análise de seus resultados indicou que a blenda propiciou a formação de um tecido fibrocartilaginoso com células do tipo fibrocondrócito e que permitiu a proteção das cartilagens articulares quando comparado ao grupo controle sem implante.

Os poli(hidroxi ácidos) são considerados uma das famílias de polímeros mais atrativas e promissoras, pois além de biorreabsorvíveis, são também biocompatíveis. O poli(hidroxi butirato) (PHB) é um dos PHAs mais estudados e possui propriedades termoplásticas semelhantes às do polipropileno ${ }^{[19]}$. Porém, devido ao seu elevado grau de cristalinidade e a sua fragilidade mecânica, apresenta aplicações limitadas.

A fim de se obter um material com melhores características, o PHB pode ser modificado através de misturas físicas com outros polímeros que sejam também hidroliticamente degradáveis ${ }^{[20]}$. A poli( $p$-dioxanona) (PPD) pode agir como plastificante polimérico melhorando a flexibilidade da blenda ${ }^{[21]}$, reduzindo a viscosidade do fundido, abaixando a temperatura de transição vítrea e diminuindo seu módulo de elasticidade, visando o emprego desses filmes em diversas áreas ${ }^{[22]}$.

Sabe-se que a biocompatibilidade destes materiais está diretamente associada ao comportamento das células em contato com o material e particularmente pela adesão na superfície ${ }^{[23]}$. Para tanto, a interação célula-suporte deve ser avaliada in vitro para se firmar condições de adesão, crescimento e diferenciação celular, como requisitos essenciais para a formação de um neotecido, e é um parâmetro importante em estudos da biocompatibilidade e citocompatibilidade ${ }^{[24]}$.

O objetivo deste trabalho foi avaliar a influência de blendas de poli(p-dioxanona) (PPD) e poli(hidroxi butirato) (PHB) na adesão celular e crescimento in vitro de fibrocondrócitos.

\section{Experimental}

\section{Preparação das blendas poliméricas}

Utilizou-se o PHB comercial Sigma-Aldrich ${ }^{\circledR}$ e a PPD na forma de sutura violeta (Ethicon, Inc). O corante foi previamente extraído em diclorometano $\left(\mathrm{CH}_{2} \mathrm{Cl}_{2}\right)$. A PPD e o PHB foram dissolvidos separadamente em hexafluorisopropanol (HFIP) para formar soluções $5 \%(\mathrm{~m} / \mathrm{v})$ até a completa homogeneização. As soluções foram misturadas e vertidas em um molde de vidro $(50 \times 30 \times 5 \mathrm{~mm})$, nas composições (100/0), (60/40), (50/50), e acondicionadas em uma câmara para evaporação do solvente por 24 horas. Os filmes foram secos em estufa a vácuo a $60{ }^{\circ} \mathrm{C}$ durante 24 horas.

\section{Obtenção de fibrocondrócitos a partir de menisco de coelhos}

As culturas de fibrocondrócitos foram isoladas a partir de meniscos dos joelhos de 5 coelhos albinos (Nova Zelândia) com cerca de três meses, de acordo com adaptações de Figueiredo e Joazeiro ${ }^{[25]}$. Os animais foram sacrificados por aprofundamento de anestesia. As fibrocartilagens foram retiradas através da secção transversal da cápsula articular e coleta dos meniscos mediais e laterais, os quais foram fragmentados e submetidos à digestão enzimática em meio DMEM (Meio Eagle Modificado por Dulbecco) com $1 \mathrm{mg} \cdot \mathrm{mL}^{-1} \mathrm{de}$ colagenase tipo IA $\left(\right.$ Sigma $\left.^{\circledR}\right)$ durante 3 horas a $37{ }^{\circ} \mathrm{C}$. As células foram centrifugadas com subsequente ressuspensão em meio DMEM contendo $10 \%$ de soro fetal bovino (SFB). Em seguida foi realizada a quantificação da viabilidade celular com Azul de Tripan. Os fibrocondrócitos obtidos foram semeados em uma densidade de $10^{5}$ células. $\mathrm{mL}^{-1}$ em placas de cultura de 96 poços (Techno Plastic Products $^{\circledR}$, Suíça) contendo as blendas de PPD/PHB 100/00, 60/40 e 50/50 em meio DMEM com SFB (10\%) para a realização dos experimentos. As membranas foram previamente incubadas a $37{ }^{\circ} \mathrm{C}$ com 5\% de $\mathrm{CO}_{2}$ conforme as normas da ISO 10993-5 $5^{[26]}$.

\section{Ensaio de adesão celular inicial e citotoxicidade direta}

Para estas análises uma modificação do método de Murakami et al. ${ }^{[27]}$ foi utilizado. Empregaram-se discos de teflon e a própria placa de poliestireno tradicionalmente utilizada respectivamente como controle negativo e positivo nos ensaios de adesão celular. Para determinar a citotoxicidade das blendas, a placa de poliestireno foi utilizada como controle negativo e fenol $(1 \%)$ como controle positivo. As placas foram incubadas durante 2 horas para análise de adesão e 24 horas para análise da citotoxicidade. Após estes tempos os poços foram lavados com DMEM. Posterior a lavagem, adicionou-se a cada poço $200 \mu \mathrm{L}$ de DMEM com $20 \mu \mathrm{L}$ de 3-(4,5-dimetiltiazol-2-il)-2,5 difenil brometo tetrazolium MTT ( $5 \mathrm{mg} \cdot \mathrm{mL}^{-1}$ ), seguindo-se um período de incubação de 4 horas a $37{ }^{\circ} \mathrm{C}$ no escuro. Posteriormente, foi adicionada a cada poço uma solução de $200 \mu \mathrm{L}$ de dimetilsulfóxido (DMSO) com $25 \mu \mathrm{L}$ de tampão Glicina/Sorensen. Alíquotas de $100 \mu \mathrm{L}$ destas soluções foram transferidas para uma nova placa e a absorbância medida em leitor de microplacas (BioTek ${ }^{\circledR}$, Elx 800, USA) a $570 \mathrm{~nm}$.

\section{Microscopia eletrônica de varredura (MEV)}

Os fibrocondrócitos foram observados após 6, 24, 48 e 120 horas de cultivo. As amostras foram fixadas durante 1 hora em solução contendo 2,5\% paraformaldeído, 2,5\% glutaraldeído, 0,06\% ácido pícrico e $1 \%$ ácido tânico, dissolvidos em tampão cacodilato $0,1 \mathrm{M}$, pH 7,4. e pós-fixadas com tetróxido de ósmio $1 \%$. Posteriormente, as amostras foram desidratadas em concentrações crescentes de etanol, secas em Ponto Crítico (Balzers ${ }^{\circledR}$ CTD 030), recobertas por ouro (Balzers ${ }^{\circledR}$ SCD 050) e observadas em microscópio eletrônico de varredura $\left(\right.$ JEOL $^{\circledR}$ JXA-840A).

\section{Ensaio colorimétrico - Sirius Red}

Neste ensaio utilizou-se a metodologia de Tullberg-Reinert e Jundt ${ }^{[28]}$, como descrito a seguir. O método é baseado na ligação seletiva do Sirius Red, um corante aniônico, com proteínas colágenas e tem sido aplicado para quantificação estimada de colágeno sintetizado em cultura de células ${ }^{[29-32]}$. Empregou-se a própria placa de poliestireno (Techno Plastic Products ${ }^{\circledR}$, Suíça) como controle $(n=6)$. As células foram cultivadas durante 14 dias. As amostras foram fixadas com Fluído de Bowin por 1 hora e coradas com Sirius Red. Após 1 hora, procedeu-se a lavagem com ácido hidroclórico 0,01 M por 30 segundos. Em seguida, o corante foi retirado das camadas celulares com $\mathrm{NaOH}$ 0,1 M durante 30 minutos. Alíquotas de $100 \mu \mathrm{L}$ das soluções contidas nos poços foram transferidas para uma nova placa. A absorbância foi medida em 570 nm $\left(\right.$ BioTek $^{\circledR}$, Elx 800, USA).

\section{Análise estatística}

Para os dados quantitativos utilizou-se o teste ANOVA, com níveis de significância $\alpha=0.05$.

\section{Resultados e Discussão}

\section{Ensaio de adesão celular inicial e citotoxicidade direta}

Os resultados do teste ANOVA mostraram uma diferença significante $(\mathrm{p}<0,05)$ entre as amostras na análise de adesão (Figura 1). O teste Tukey foi usado para comparar as amostras quanto à adesão celular nas blendas de PPD/PHB que foi significantemente diferente, quando comparadas ao controle negativo (teflon) $(\mathrm{p}<0,05)$. 
A blenda PPD/PHB 100/00 demonstrou ter uma maior afinidade com as células, apresentando maiores índices de absorbância, se comparada ao controle positivo (poliestireno) e as blendas 60/40 e $50 / 50(\mathrm{p}<0,05)$. Não havendo, portanto diferença estatística entre as blendas $60 / 40$ e $50 / 50$ e o controle positivo ( $p>0,05)$.

Após 24 horas de cultivo (Figura 2), o controle positivo (fenol 1\%) utilizado na análise de citotoxicidade apresentou-se estatisticamente menor que todas as amostras $(\mathrm{p}<0,05)$. O controle negativo (poliestireno) e as blendas de PPD/PHB apresentam resultados similares, não havendo diferença significativa entre ambos ( $p>0,05$ ), considerando-se que ambos resultaram em absorbância maior do que a do controle positivo. Como os controles positivos e negativos exibiram diferença significante entre as médias $(\mathrm{p}<0,01)$, estes nos fornecem dados consistentes para controles padronizados, com os quais se podem comparar a citotoxicidade de materiais.

É conhecido que o comportamento da adesão celular, proliferação e diferenciação das células sobre materiais poliméricos dependem de características de superfície como hidrofilicidade/ hidrofobicidade, propriedades físicas, químicas, cargas, rugosidade e rigidez ${ }^{[33]}$, tanto dos materiais quanto das células, que influenciam os eventos observados na interface célula-material, resultando ou não na biocompatibilidade do dispositivo ${ }^{[34]}$. Desta forma, é essencial que o material permita a adesão e proliferação celular para subsequente regeneração tecidual.

A interação das células com os materiais depende, portanto, do reconhecimento entre a superfície receptora de adesão celular e as

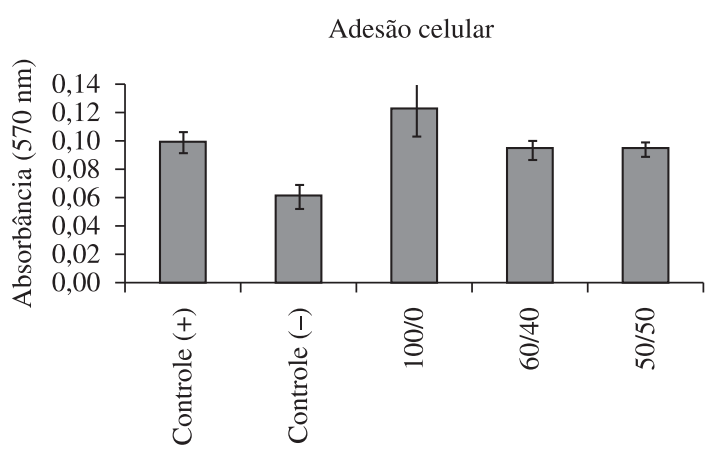

Amostras PPD/PHB

Figura 1. Adesão celular de fibrocondrócitos em membranas de PPD/PHB nas composições 100/00, 60/40 e 50/50 após 2 horas de cultivo (controle positivo $=$ placa de cultura; controle negativo $=$ discos de teflon). Os valores representam a média \pm desvio padrão $(n=6)$.

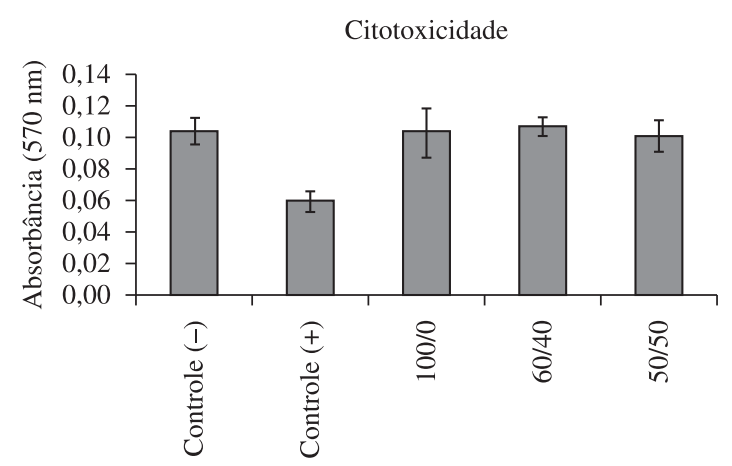

Amostras PPD/PHB

Figura 2. Citotoxicidade direta das amostras de PPD/PHB nas composições 100/0, 60/40 e 50/50 após 24 horas de cultivo com fibrocondrócitos $($ controle negativo $=$ placa de cultura; controle positivo $=$ fenol $1 \%)$. Os valores representam a média \pm desvio padrão $(n=6)$. O ensaio demonstrou resultados similares entre as blendas de PPD/PHB e o controle $(-)(\mathrm{p}>0,05)$ e ambos são superiores ao controle $(+)(\mathrm{p}<0.05)$. proteínas da matriz extracelular como a fibronectina, vitronectina e o colágeno, que possuem o domínio de ligações celulares ${ }^{[35]}$.

Poliésteres biorreabsorvíveis como o PHB apresentam fracas interações célula-matriz, apesar de sua biocompatibilidade. Os PHBs são biomateriais hidrofóbicos ${ }^{[36]}$, ou seja, apresentam ângulo de contato por volta de $80^{\circ}$.

Conforme verificado na Figura 1, a blenda 100/0 após 2 horas de cultivo apresentou adesão celular superior ao controle positivo e as blendas 60/40 e 50/50, sugerindo que a hidrofilicidade e a morfologia do material influenciaram na interação dos fibrocondrócitos com as membranas. Estes dados estão de acordo com Chu et al. ${ }^{[37]}$, uma vez que a adesão e crescimento celular são considerados como sendo fortemente influenciados pelo balanço hidrofilicidade/ hidrofobicidade da superfície, frequentemente descrito como molhabilidade.

Os resultados obtidos na análise de citotoxicidade correspondem com os encontrados na literatura, considerando que a PPD é amplamente utilizada em pacientes, sendo biocompatível ${ }^{[38]}$ e o PHB apresenta baixa toxicidade, em parte devido ao fato que se degrada in vivo em 3-hidroxibutirato, um constituinte normal do sangue e tecidos ${ }^{[39]}$. Zhao et al. ${ }^{[40]}$ já haviam demonstrado a citocompatibilidade do $\mathrm{PHB}$ na proliferação de condrócitos e da mesma forma, as blendas de PPD/PHB apresentaram-se atóxicas para os fibrocondrócitos, pois não afetaram as atividades mitocondriais das células. Embora uma substância tóxica não afete apenas uma estrutura molecular, mas sim várias funções celulares; considerou-se que a imediata medição da atividade mitocondrial pode ser o suficiente para validar a viabilidade celular ${ }^{[24]}$.

\section{Microscopia eletrônica de varredura (MEV)}

A PPD apresenta superfície irregular, composta por pequenos glóbulos pontiagudos com cerca de $50 \mu \mathrm{m}$ de diâmetro (Figura 3a), característicos do material ${ }^{[41]}$. Observa-se uma variação da morfologia nas composições 60/40 e 50/50 (Figura 3b e c), sendo que os glóbulos se tornaram menos visíveis na blenda 60/40, apresentando-se mais homogenia, quando comparada à composição 50/50, onde se verifica a formação de glóbulos pontiagudos nítidos em toda a superfície com cerca de $100 \mu \mathrm{m}$ de diâmetro.

A principal dificuldade encontrada na engenharia de tecidos quanto a um biomaterial é conciliar suas propriedades físicas, químicas e mecânicas para a funcionalidade do implante com um nível aceitável de reação inflamatória, a qual geralmente é causada por moléculas solúveis ou íons liberados dos materiais utilizados como implantes ${ }^{[42]}$.

Os resultados obtidos ao microscópio eletrônico de varredura evidenciam que as blendas de PPD/PHB, independentemente de suas composições, permitiram que os fibrocondrócitos se estabelecessem nas membranas aderindo, seguido pela extensão de projeções citoplasmáticas e posterior proliferação celular (Figura 4).

Os diferentes tempos de cultivos mostram diferenças morfológicas significativas entre os fibrocondrócitos cultivados sobre a blenda 100/0 (Figura 4a, d, g, j) e as blendas 60/40 e 50/50, sendo possível observar agrupamentos de células em certas regiões das membranas, característica esta importante para iniciar uma resposta reparadora ${ }^{[43]}$, já que os fibrocondrócitos apresentam como habilidade intrínseca aderir em pequenos grupos (grumos) celulares e esta característica pode ser perdida ao longo da primeira passagem na expansão do cultivo in vitro.

As células cultivadas sobre a blenda 100/0, após 6 horas de cultivo, apresentaram morfologia irregular envolvendo os glóbulos da PPD e evidentes prolongamentos citoplasmáticos conciliando-as (Figura 4a). Diferentemente dos contornos celulares observados nas células cultivadas sobre as blendas 60/40 e 50/50, que 


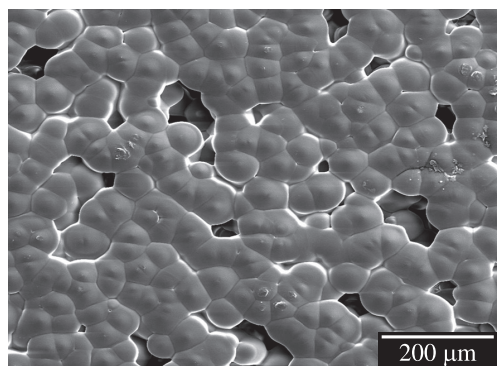

(a)

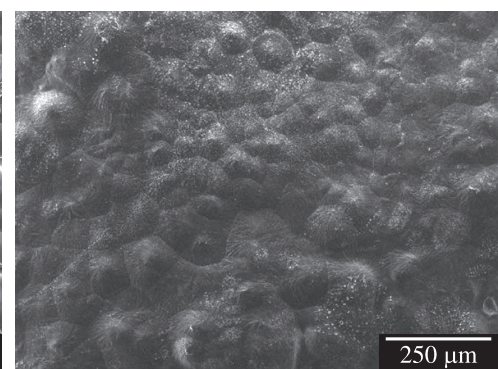

(b)

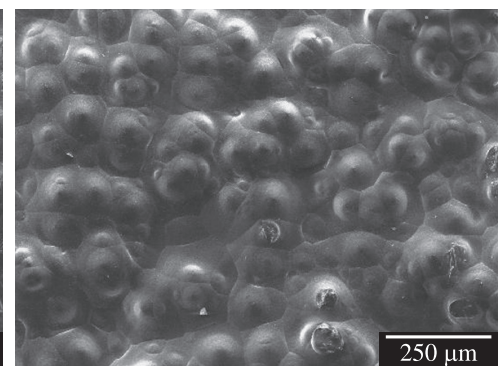

(c)

Figura 3. Microscopia eletrônica de varredura (MEV) das superfícies das blendas de PPD/PHB. a) PPD/PHB (100/0); b) PPD/PHB (60/40); e c) PPD/PHB (50/50).

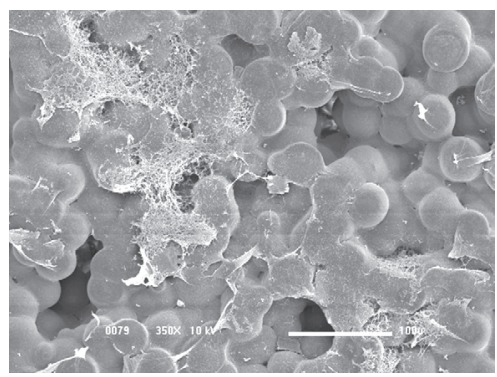

(a)

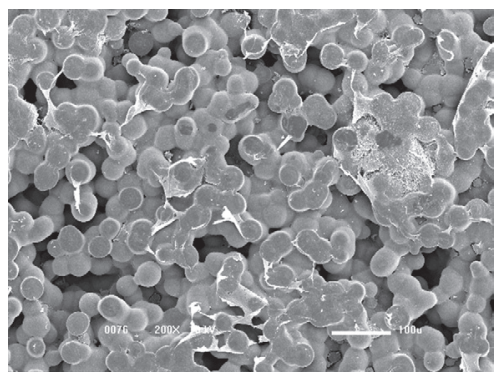

(d)

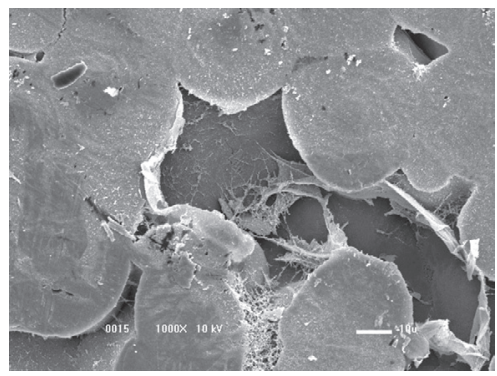

(g)

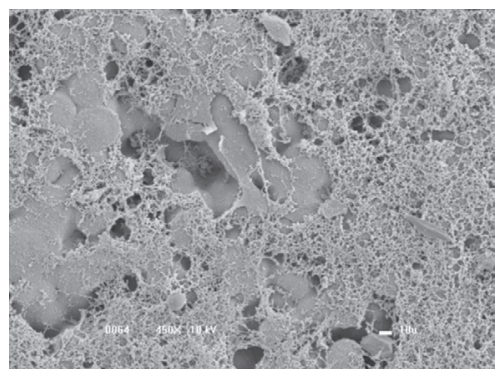

(j)

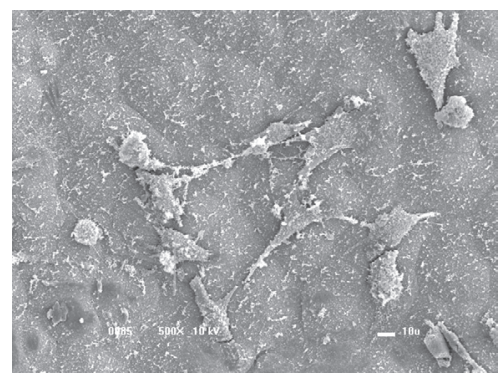

(b)

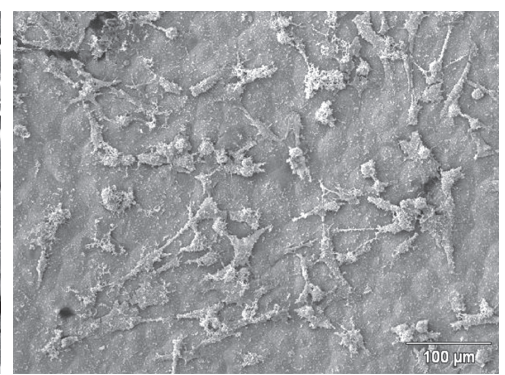

(e)

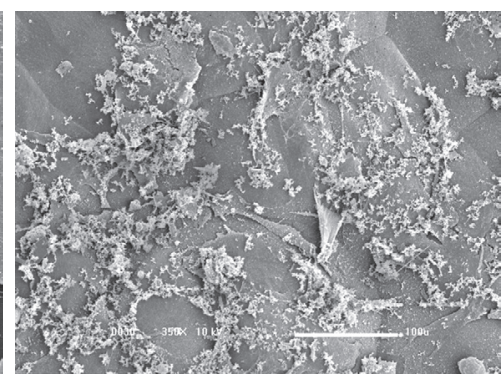

(h)

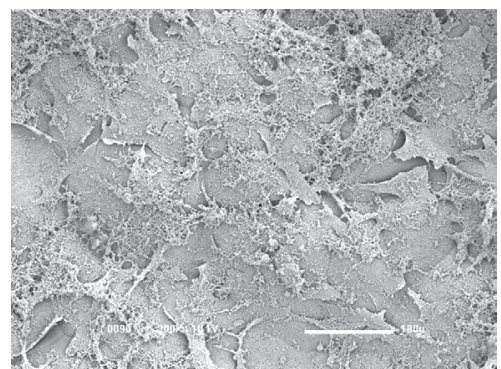

(k)

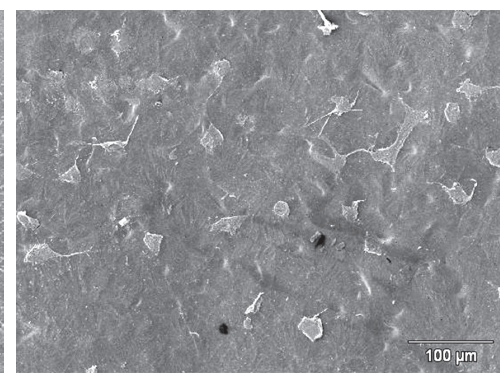

(c)

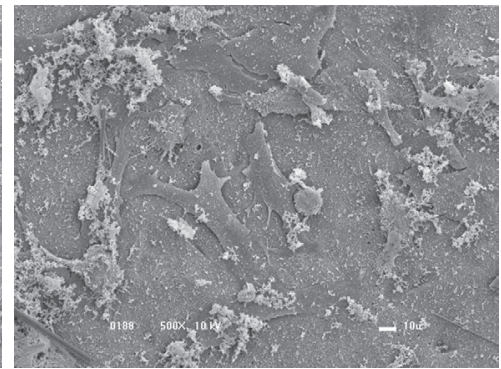

(f)

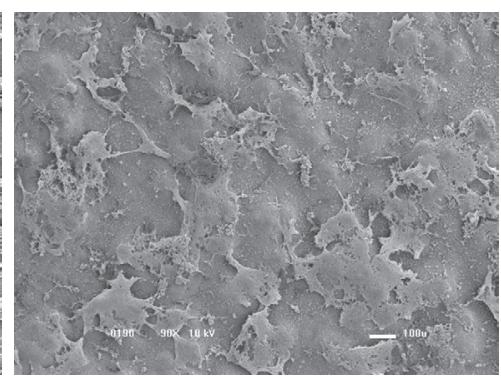

(i)

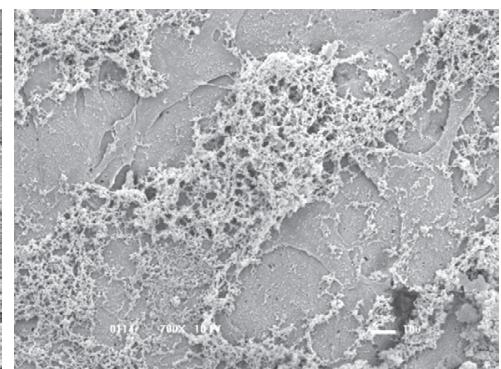

(1)

Figura 4. Microscopia eletrônica de varredura (MEV) de fibrocondrócitos sobre as blendas de PPD/PHB em diferentes tempos de cultivo. a) PPD/PHB 100/0, 6 horas; b) PPD/PHB 60/40, 6 horas; c) PPD/PHB 50/50, 6 horas; d) PPD/PHB 100/0, 24 horas; e) PPD/PHB 60/40, 24 horas; f) PPD/PHB 50/50, 24 horas; g) PPD/PHB 100/0, 48 horas; h) PPD/PHB 60/40, 48 horas; i) PPD/PHB 50/50, 48 horas; j) PPD/PHB 100/0, 120 horas; k) PPD/PHB 60/40, 120 horas; e 1) $\mathrm{PPD} / \mathrm{PHB} 50 / 50,120$ horas. 
mostraram perfis predominantemente arredondados, com início de prolongamentos celulares (Figura 4b, c). No entanto, tal fato pode ser um possível indicador de que os fibrocondrócitos cultivados sobre estes substratos não haviam completado ainda o processo de espraiamento, já que esta morfologia foi predominantemente constatada neste tempo de cultivo, considerando-se que a adesão lenta a substratos de PHB é algo já descrito na literatura ${ }^{[44-45]}$.

Sabe-se que uma vez estabelecida a adesão sobre o substrato, as células se espalham, ampliando sua área de contato com o mesmo ${ }^{[46]}$. A natureza da matriz influencia principalmente programas de crescimento, proliferação, diferenciação e apoptose, ou até mesmo vários dos parâmetros citados de forma simultânea. As células percebem os sinais e reagem ao substrato, a exemplo MEC, por meio de sinais dependentes da ativação de integrinas e mediadores intracelulares, produzindo respostas altamente dinâmicas que podem levar à reorganização do citoesqueleto e alterações de funções em resposta a sinais mecânicos externos ${ }^{[47-48]}$, com consequentes modificações da forma, influenciada pela topografia do substrato, que contribui para seu comportamento fenotípico.

Após 24 horas de cultivo, os fibrocondrócitos cultivados sobre as blendas 60/40 e 50/50 apresentam-se com perfis alongados e achatados característicos ${ }^{[49]}$, com inúmeros prolongamentos de contato com aspecto fino e sobrepostos uns aos outros, diferentemente das células cultivadas sobre as membranas de PPD pura que apresentam morfologia irregular em torno dos glóbulos, envolvendo-os (Figura 4d) sugerindo que o aspecto fenotípico dos fibrocondrócitos foi alterado devido às características morfológicas do material.

Estas diferenças morfológicas abrem perspectivas para a investigação do ganho ou perda de componentes pré-específicos para respostas adaptativas relacionados à manutenção da plasticidade celular em diversos substratos de acordo com os processos que induzem transições fisiológicas específicas para diferentes tipos celulares e ambientes ${ }^{[50]}$.

Nas imagens observadas após 48 e 120 horas de cultivo, nota-se um aumento crescente na densidade de células e presença de grande quantidade de material particulado sobre as membranas, devido a deposição continua de elementos fibrilares sintetizados, dificultando a identificação/distinção entre os fibrocondrócitos e o material orgânico depositado, visto que as células mostraram-se muito bem aderidas, achatadas e com grandes projeções citoplasmáticas. Indicando o início da formação de um tapete celular de difícil distinção, pois existem grupos de células unidos próximos da confluência, onde é impossível identificar os limites citoplasmáticos entre elas.

Sabe-se que a presença de elementos fibrilares depositados junto às células evidencia que a célula manteve sua capacidade

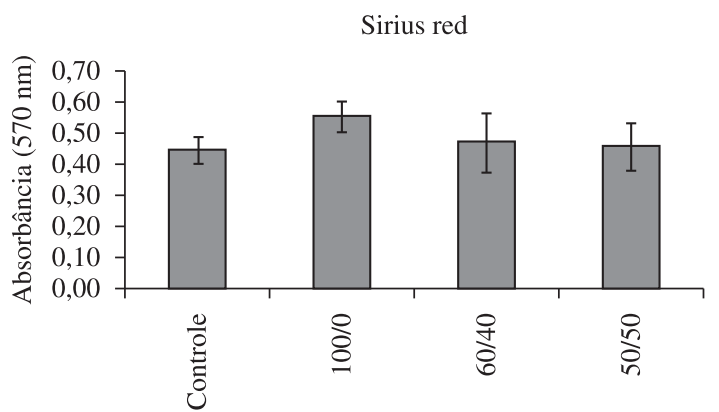

Amostras 14 dias

Figura 5. Análise colorimétrica com o corante Sirius Red nas amostras de PPD/PHB nas composições 100/0, 60/40, 50/50 e controle (placa de poliestireno) após 14 dias de cultivo. O ensaio apresentou resultados similares entre as blendas de PPD/PHB e o controle ( $p>0,05)$. biossintética ${ }^{[17]}$ e que a adesão de células ao substrato não somente estimula a proliferação, mas também sua atividade biossintética ${ }^{[51]}$.

Estes resultados também foram observados por Silva ${ }^{[17]}$, onde os fibrocondrócitos cultivados sobre membranas de PLLA tendem a aderir de forma achatada, multiplicando-se até formar uma monocamada, e condizem com a literatura, onde membranas de PPD e PHB, quando utilizadas como substrato para cultura celular, permitiram a proliferação das células e a capacidade de síntese $^{[40,52,53]}$.

\section{Ensaio colorimétrico - Sirius Red}

O ensaio reflete a quantidade de colágeno disposto na matriz extracelular secretada pelos fibrocondrócitos. Os resultados do teste ANOVA demonstraram que não ocorreu diferença significante ( $\mathrm{p}>0,05)$ entre as blendas e o controle utilizado na análise (Figura 5).

Independente do tecido lesado, o colágeno, do ponto de vista funcional, é o componente mais importante na reparação dos tecidos ${ }^{[54]}$. O colágeno também está envolvido nos processos de adesão, diferenciação, migração e proliferação celular ${ }^{[55]}$.

A fibrocartilagem é um tecido conjuntivo avascular, formado por poucas células e uma grande quantidade de matriz extracelular constituída principalmente de colágeno, cerca de $85-95 \%$ do tecido, e proteoglicanos de $2-3 \%$ do peso seco $^{[56]}$. Estas moléculas apresentam importantes funções biomecânicas ${ }^{[57]}$. O colágeno do tipo I é um dos principais colágenos encontrados nesta matriz ${ }^{[58]}$. Naumann et al. ${ }^{[59]}$ caracterizaram os componentes da matriz extracelular do menisco de coelhos e observaram marcação positiva para elastina e colágeno VI na proximidade das células do menisco.

Os fibrocondrócitos mantêm o equilíbrio da matriz extracelular através dos mecanismos de síntese e degradação, de forma que o controle destas taxas de forma compatível pode levar ao sucesso do reparo, integração e funcionamento do dispositivo usado ${ }^{[57]}$. Quando este equilíbrio é alterado, a função da fibrocartilagem é prejudicada possibilitando o surgimento de osteoartrite precoce ${ }^{[60]}$.

A análise dos resultados aqui apresentados confirma as observações realizadas por Tanaka et al. ${ }^{[61]}$, Deng et al. ${ }^{[52]}$, e Silva ${ }^{[17]}$, onde parâmetros bioquímicos e morfológicos foram utilizados para demonstrar a viabilidade da cultura celular, que apresentou a capacidade de manter sua morfologia e sintetizar matriz extracelular.

Apesar dos resultados encontrados não apresentarem diferenças significativas entre as composições das blendas, acredita-se que intervalos de tempos de cultivo menores poderiam refletir em importantes comparações da quantidade de colágeno disposto em relação aos achados estatísticos.

\section{Conclusão}

Pode-se concluir que a morfologia das blendas de PPD/PHB variou em função da composição das mesmas, influenciando a morfologia celular, indicando que os fibrocondrócitos podem apresentar diferentes perfis fenotípicos em resposta a alterações no substrato. As blendas não se apresentaram citotóxicas e permitiram a adesão dos fibrocondrócitos, evidenciando-se a capacidade de manutenção da síntese de matriz extracelular para todas as composições.

\section{Agradecimentos}

Os autores agradecem a FAPESP pelo suporte financeiro concedido, $\mathrm{n}^{\circ}$ do processo 2006/07146-7, a Dra. Betina Mara Pereira Ferreira e ao Laboratório de Luz Sincroton pela realização das análises de MEV. 


\section{Referências Bibliográficas}

1. Carlson, B. M. - Anat. Rec. B New Anat., 287B, p.4 (2005).

2. Risbud, M. V. \& Sittinger, M. - Trends Biotechnol., 20, p.351 (2002).

3. Badylak, S. F. - Semin. Cell Dev. Biol., 13, p.377 (2002).

4. Hoshiba, T.; Cho, C. S.; Murakawa, A.; Okahata, Y. \& Akaike, T. Biomaterials, 27, p.4519 (2006).

5. Messner, K. \& Gao, J. - J. Anat. P2, 193, p.161 (1998).

6. Pangborn, C. A. \& Syriacos, A. A. - J. Orthop. Res., 23, p.1184 (2005).

7. Reguzzoni, M.; Manelli, A.; Ronga, M.; Raspanti, M. \& Grassi, F. - J. Biomed. Mater. Res. Part B Appl. Biomater., 74, p.808 (2005).

8. Chiari, C.; Koller, U.; Dorotka, R.; Eder, C.; Plasenzotti, R.; Lang, S.; Ambrosio, L.; Tognana, E.; Kon, E.; Salter, D. \& Nehrer, S. - Osteoarthr. Cartil., 14, p.1056 (2006).

9. Baker, B. M. \& Mauck, R. L. - Biomaterials, 28, p.1967 (2007).

10. Tienen, T. G.; Heijkants, R. G. J. C.; Buma, P.; De Groot, J. H.; Pennings, A. J. \& Veth, R. P. H. - Biomaterials, 24, p.2541 (2003).

11. Fan, H.; Hu, Y.; Zhang, C.; Li, X.; Lu, R.; Qin, L. \& Zhu, R. Biomaterials, 27, p.4573 (2006).

12. Tienen, T. G.; Heijkants, R. G. J. C.; De Groot, J. H.; Schouten, A. J.; Pennings, A. J.; Veth, R. P. H. \& Buma, P. - J. Biomed. Mater. Res. Part B Appl. Biomater, 76, p.389 (2006).

13. Weinand, C.; Peretti, G. M.; Adams, S. B.; Bonassar, L. J.; Randolph, M. A. \& Gill, T. J. - Am. J. Sports Med., 34, p.1779 (2006).

14. Becker, R.; Wirz, D.; Wolf, C.; Gopfert, B.; Nebelung, W. \& Friederich, N. - Arch. Orthop. Traum. Surg., 125, p.254 (2005).

15. Kang, S.; Son, S.; Lee, J.; Lee, E.; Lee, K.; Park, S.; Park, J. \& Kim, B. - J. Biomed. Mater. Res. A, 78, p.659 (2006).

16. Pinto, M. R. F.; Elisama, C. M.; Alberto-Rincon, M. C. \& Duek, E. A. R. - Ver. Mater., 2010 (in press).

17. Silva, D. R. M. - "Membranas de poli-l(ácido lático): suporte para fibrocondrócitos isolados de menisco e comportamento in vivo no tecido subcutâneo", Tese de Doutorado, Universidade Estadual de Campinas, Brasil (2007).

18. Pezzin, A. P. T.; Cardoso, T. P.; Rincon, M. C. A.; Zavaglia, C. A. C. \& Duek E. A. R. - Artif. Organs, 27, p.428 (2003).

19. Duarte, M. A. T.; Julio, C. F.; Martins, E. S. \& Pezzin, S. H. - Ver. Mater., 9, p.386 (2004)

20. Schneider, A. L. S. - "Produção, caracterização e degradação em solos de plásticos biodegradáveis", Tese de Doutorado, Universidade Federal de Santa Catarina, Brasil (2006).

21. Pezzin, A. P. T.; Zavaglia, C. A. C. \& Duek, E. A. R. - Polímeros, 12, p.285 (2002).

22. Prazeres, L.; Garcia, M. C. F.; Duek, E. A. R.; Esposito, A. R.; Schneider, A. L. S. \& Pezzin, A. P. T. - Rev. UNIVILLE, 14, p.52 (2009).

23. Anselme K. - Biomaterials, 21, p.667 (2000).

24. Lucchesi, C.; Ferreira, B. M. P.; Duek, E. A. R.; Santos, A. R. \& Joazeiro, P. P. - J. Mater. Sci. Mater. Med., 19, p.635 (2008).

25. Figueiredo, C. A. \& Joazeiro, P. P. - Rev. Instituto Adolfo Lutz, 64, p.263 (2005).

26. ISO 109935, 1992 (E) - "Biological evaluation of medical devices - part 5 - Tests for cytotoxicity: in vitro methods" (1992).

27. Murakami, N.; Fukuchi, S.; Takeuchi, K.; Hori, T.; Shibamoto, S. \& Ito, F. - J. Cell Physiol., 176, p.127 (1998).

28. Tullberg-Reinert, H. \& Jundt, G. - Histochem. Cell Biol., 112, p.271 (1999).

29. Saruwatari, L.; Aita, H.; Butz, F.; Nakamura, H. K.; Ouyang, J.; Yang, Y.; Chiou, W. A. \& Ogawa, T. - J. Bone Miner. Res., 20, p.2002 (2005).

30. Mas, B. A.; Esposito, A. R.; Dutra, A. M.; Duek, E. A. R. \& Aragones, A. - "Cultura de osteoblastos sobre arcabouços de PLDLA", in: Anais do $18^{a}$ Congresso Brasileiro de Engenharia e Ciências dos Materiais. Porto de Galinhas - PE (2008).

31. Messias, A. D.; Aragones, A. \& Duek, E. A. R. - Key Eng. Mater., 396-398, p.461 (2009).
32. Esposito, A. R.; Aragones, A. \& Duek E. A. R. - "Cellular behaviour of knee meniscal fibrochondrocytes-like cells culture on PLGA and PLDLA scaffolds" in: Proceedings of Internacional Conference on Tissue Engineering, IST Press, Lisboa, p. 131 (2009).

33. Wan, Y.; Wang, Y.; Liu, Z.; Qu, X.; Han, B.; Bei, J. \& Wang, S. Biomaterials, 26, p.4453 (2005).

34. Cai, K.; Rechtenbach, A.; Hao, J., Bossert, J. \& Jandt, K. D. Biomaterials, 30, p.5960 (2005).

35. Yang, J.; Bei, J. \& Wang, S. - Biomaterials, 23, p.2607 (2002).

36. Hasirci, A.; Tezcaner, N.; Hasirci \& Suzer, S. - J. Appl. Polym. Sci., 87, p.1285 (2003).

37. Chu, P. K.; Chen, J. Y.; Wang, L. P. \& Huang, N. - Mater. Sci. Eng. R. Rep., 36, p.143 (2002).

38. Chusak, R. B. \& Dibbell, D. G. - Plast. Reconstr. Surg., 72, p.217 (1983).

39. Reusch, R. N.; Sparrow, A. W. \& Gardinner, J. - Biochim. Biophys. Acta, 1123, p.33 (1992).

40. Zhao, K.; Deng, Y. \& Chen, J. C. - Biomaterials, 24, p.1041 (2003).

41. Pezzin, A. P. T.; Alberta Van Ekenstein, G. O. R. \& Duek, E. A. R. Polymer, 42, p.8303 (2001).

42. Prazeres, L.; Grigull, V. H.; Garcia, M. C. F.; Duek, E. A. R.; Esposito, A. R.; Schneider, A. S. \& Pezzin, A. P. T. - "Avaliação da miscibilidade de blendas de poli(p-dioxanona) e poli(3-hidroxibutirato)", in: Anais do $9^{\circ}$ Congresso Brasileiro de Polímeros. Campina Grande - PB, out (2007).

43. Araújo, V. G. - "Estudo ultra-estrutural da matriz extracelular dos grumos celulares formados na cultura de fibrocondrócitos de meniscos de coelhos", Tese de Mestrado, Universidade UNIFESP, Brasil (2002).

44. Ferreira, B. M. P. - "Obtenção, caracterização, estudo in vitro e in vivo de blendas de PLLA/PHBV', Tese de Doutorado, Universidade Estadual de Campinas, Brasil (2002).

45. Santos Jr., A. R.; Ferreira, B. M. P.; Duek, E. A. R.; Dolder, H.; Wada, R. S. \& Wada, M. L. F. - Artif. Organs, 28, p.381 (2004).

46. Santos Jr., A. R. \& Wada, M. L. F. - Polímeros, 17, p.308 (2007).

47. Owen, G.; Meredith, D. O.; Gwynn, I. \& Richards, R. G. - Eur. Cell. Mater., 9, p.85 (2005).

48. Georges, P. C. \& Janmey, P. A. - J. Appl. Physiol., 98, p.1547 (2005).

49. Verdonk, P. C. M.; Forsyth, R. G.; Wang, J.; Almqvist, K. F.; Verdonk, R.; Veys, E. M. \& Verbruggen, G. - Osteoarthr. Cartil., 13, p.548 (2005).

50. Friedl, P. - Curr. Opin. Cell Biol., 16, p.14 (2004).

51. Lombello, C. B.; Malmonge, S. M. \& Wada, M. L. F. - Cytobios, 101, p.115 (2000).

52. Deng, Y.; Lin, X.; Zheng, Z.; Deng, J.; Chen, J.; Ma, H. \& Chen, G. Biomaterials, 24, p.4273 (2003).

53. Itthichaisri, C.; Wiedmann-al-ahmad, M.; Huebner, U.; Al-ahmad, A.; Schoen, R.; Schmelzeisen, R. \& Gellrich, N. C. - J. Biomed. Mater. Res. A, 82, p.777 (2007).

54. Thornton, F. J. \& Barbul, A. - Surg. Clin. North Am., 77, p.549 (1997).

55. Stevens, A. \& Lowe, J. - "Histologia", Manole, São Paulo (1995).

56. McDevitt, C. A. \& Webber, R. J. - Clin. Orthop. Relat. Res., 252, p.8 (1990).

57. Abraham, L. C.; Dice, J. F.; Finn, P. F.; Mesires, N. T.; Lee, K. \& Kaplan, D. L. - Biomaterials, 28, p.151 (2007).

58. Gunja, N. J. \& Athanasiou, K. A. - Arth. Res. Ther., 9, p.1 (2007).

59. Naumann, A.; Dennis, J. E.; Awadallah, A.; Carrino, D. A.; Mansour, J. M.; Kastenbauer, E. \& Caplan, A. I. - J. Histochem. Cytochem., 50, p.1049 (2002).

60. Calvo, E.; Palacios, I.; Delgado, E.; Ruiz-Cabello, J.; Hernandez, P.; Sanchez-Pernaute, O.; Egido, J. \& Herrero-Beaumong - Osteoarthr. Cartil., 9, p.463 (2001).

61. Tanaka, T.; Fujii, K. \& Kumagae, Y. - Knee Surg. Sports Traumatol. Arthrosc., 7, p.75 (1999).

Enviado: 28/09/09

Reenviado: 05/04/10

Aceito: $24 / 06 / 10$

DOI: $10.1590 / \mathrm{S} 0104-14282010005000062$ 